\title{
IDENTIFICATION OF STAPHYLOCOCCI BY PYROLYSIS GAS-LIQUID CHROMATOGRAPHY
}

\author{
J. T. MageE*, J. M. Hindmarch and D. F. Meechan $\dagger$ \\ Department of Bacteriology, Royal Hallamshire Hospital, Sheffield S10 2JF and \\ $\dagger$ Department of Community Medicine, University of Sheffield Medical School, Beech \\ Hill Road, Sheffield S10 2RX
}

\begin{abstract}
SUmmaRY. The identification of bacteria by pyrolysis gas-liquid chromatography (PGLC) was evaluated with the genus Staphylococcus. A matrix containing the characteristics of seven species of Staphylococcus was constructed from the results obtained with 42 named strains identified by biochemical methods. An identification program based upon this database was evaluated in tests with 100 isolates of catalase-positive oxidase-negative gram-positive cocci identified by biochemical and PGLC systems. Agreement between the two systems was $90 \%$. Pure cultures of unknown isolates were identified within 30 min by PGLC using a microcomputer data acquisition and analysis program. A taxonomic analysis of the data is presented, and methods for quality control of PGLC, prolongation of column life, and data analysis are described and discussed.
\end{abstract}

\section{INTRODUCTION}

In pyrolysis gas-liquid chromatography (PGLC), thermolytic cleavage of chemical bonds in a specimen heated in an inert atmosphere yields characteristic low-molecularweight products that are separated and quantitated by gas-liquid chromatography (Drucker, 1976). In Curie-point pyrolysis the heat is produced by magnetic induction in a ferromagnetic carrier coated with the specimen (Buhler and Simon, 1970).

The application of pyrolysis techniques to bacterial identification was reviewed by Gutteridge and Norris (1979); this technique offers the prospect of rapid identification of isolates. Analysis times of $8 \mathrm{~min}$ (French, Phillips and Chinn, 1981) to $45 \mathrm{~min}$ (Oxborrow, Fields and Puleo, 1976) have been described and the technique has been applied to a wide range of organisms (Reiner and Ewing, 1968; Oxborrow et al., 1976; Wickman, 1977; Stack et al., 1977; French, Gutteridge and Phillips, 1980). However, several difficulties have been encountered, including the short life of the columns (Sekhon and Carmichael, 1973; Seviour, Chilvers and Crow, 1974; French et al., 1980) and lack of reproducibility between different sets of apparatus (Stack et al., 1977; French et al., 1980).

Received 11 Nov. 1982, revised version accepted 31 May 1983.

* Present address: Department of Bacteriology, Children's Hospital, Western Bank, Sheffield S10 2TH. 
The aim of this study was to develop a rapid method for the identification of common species of Staphylococcus by PGLC and to evaluate it in conditions appropriate to a routine diagnostic laboratory. PGLC required only minor additions to the chromatograph in routine use for the detection and identification of anaerobes. The genus Staphylococcus was chosen because there has been recent interest in the identification and taxonomy of the group (Kloos and Schleifer, 1975a; Schleifer and Kloos, 1975; Feltham, 1979; Feltham and Sneath, 19.82), and because problems of isolation and maintenance of strains are minimal.

\section{MATERIALS AND METHODS}

PGLC equipment. A Pye-Unicam series 204 gas-liquid chromatograph (Pye-Unicam, York Street, Cambridge CB1 2PX) with dual flame ionisation detectors, gas flow control unit, temperature programming unit, and a Phillips 8251 chart recorder, was in routine use for the identification of anaerobes. To this were added (i) a Pye-Unicam Curie point pyrolyser, (ii) a 16 channel eight-bit analogue to digital converter (ADC; Digital Design and Development, 18/19 Warren Street, London W1P 5DB), (iii) a Commodore 3016 microcomputer (Commodore Systems, 675 Ajax Avenue, Trading Estate, Slough, Bucks) and (iv) a Commodore 3022 dot-matrix printer. A buffer-amplifier circuit was used to match the $10 \mathrm{~V}$ integrator output of the chromatograph to an input channel of the ADC which transmitted a 0-255 digital output to the computer, corresponding to a zero to full-scale deflection of the chart recorder pen. A 10-fold attenuated output from the buffer-amplifier to a second channel of the ADC allowed the computer to accept readings beyond the normal scale. The computer was programmed to measure the retention times and heights of peaks in the output and to print the results after each analysis. Copies of the BASIC listing are available from J.T. Magee.

Bacterial strains and biochemical identification. One hundred and forty two strains of catalase-positive oxidase-negative gram-positive cocci were examined; 113 were isolated in the routine laboratory, and 29 that had been characterised in a previous study (Feltham, 1979) were kindly supplied by Dr R.K.A. Feltham (Public Health Laboratory, Leicester Royal Infirmary, Infirmary Square, Leicester LB1 5WW). The cultures were stored in $15 \%$ glycerol broth at $-20^{\circ} \mathrm{C}$. The strains were examined for their reactions in the following biochemical tests, using the methods of Kloos and Schleifer (1975a) unless otherwise stated: production of free and bound coagulase (methods 2 and 3; Cowan, 1974), phosphatase (Feltham, 1979), acetylmethyl carbinol (method 1; Cowan, 1974) and deoxyribonuclease; reduction of nitrate (method 1; Cowan, 1974); colony size and haemolysis on human-blood agar; colony pigmentation; growth on glycerol-erythromycin agar; and production of acid from arabinose, ribose, xylose, galactose, glucose, fructose, mannose, rhamnose, mannitol, sorbitol, xylitol, salicin, maltose, lactose, sucrose, trehalose, and melezitose. Twenty strains were tested in duplicate to assess test reproducibility. The strains were identified on the basis of the test results according to the simplified scheme of Kloos and Schleifer $(1975 b)$. The identification was verified by comparison with the descriptions of the accepted species (Kloos and Schleifer, 1975a; Schleifer and Kloos, 1975), noting discrepant results for those tests to which the descriptions assigned a frequency of $>80 \%$ or $<20 \%$ for positive reactions. Strains that differed in more than two reactions from each of the described species were regarded as unidentified.

Forty two of the strains were used to establish the characteristics of seven species of Staphylococcus in PGLC. They comprised eight strains each of S. aureus, S. saprophyticus and $S$. epidermidis, five strains each of $S$. haemolyticus and $S$. hominis, and four strains each of $S$. capitis and S. cohni. This group included the type strains of S. capitis (ATCC27840) S. cohni (ATCC29974), S. haemolyticus (ATCC29970) and S. hominis (ATCC27844) and 12 other strains donated by Dr Feltham (three strains each of S. capitis, S. cohni, S. haemolyticus and S. hominis). The other 26 strains were from the routine laboratory. The data derived from PGLC study of these strains were used to produce the PGLC identification scheme in which the remaining 100 strains ( 13 from Dr Feltham and 87 laboratory isolates) were examined.

Pyrolysis and GLC technique. Test strains were grown aerobically for $18 \mathrm{~h}$ at $37^{\circ} \mathrm{C}$ on blood agar (defibrinated horse blood, Difco, 5\%, in Blood Agar Base No.2, Lab-M). Five to ten 
colonies were picked from the surface with a nichrome loop and inserted into the end of a capillary tube (i.d. $0.8 \mathrm{~mm}$ ) to give a plug c. $5 \mathrm{~mm}$ in length. The distal end of the pyrolysis wire (Curie point $610^{\circ} \mathrm{C}$, Pye-Unicam) was heated to red heat, cooled, inserted $c .1 \mathrm{~cm}$ into the capillary tube, rotated gently and removed, care being taken not to touch it. Macroscopic aggregates of bacteria were removed and the wire with its attached septum was inserted into the chromatograph. During this procedure the column injection port was left open with carrier gas flowing to prevent entry of air into the column. A period of $3 \mathrm{~min}$ was allowed for restabilisation of the carrier gas flow rate and drying of the specimen; then, an 8-s period of pyrolysis, the chromatograph temperature program, and the computer peak recording routine, were started simultaneously.

The chromatography conditions were: injector oven temperature $190^{\circ} \mathrm{C}$, detector oven temperature $200^{\circ} \mathrm{C}$, column oven temperature $80^{\circ} \mathrm{C}$ for $2 \mathrm{~min}$ followed by a programmed increase of $12^{\circ} \mathrm{C} / \mathrm{min}$ to $185^{\circ} \mathrm{C}$ which was held for $15 \mathrm{~min}$. Detector gas flow rates were hydrogen $26 \mathrm{ml} / \mathrm{min}$ and air $260 \mathrm{ml} / \mathrm{min}$. Fine daily adjustments of the nitrogen carrier gas flow rates were made with a bubble flowmeter. The pyrolysis column flow rate was $23.1 \mathrm{ml} / \mathrm{min}$ and the balance column flow rate was adjusted to give a small positive baseline shift over the temperature program in a blank run. The computer recorded this baseline shift and subtracted an appropriate correction from each peak height recorded in subsequent pyrograms during that day. Any deviations from normal peak retention times were investigated and corrected on a daily basis.

The pyrolysis products were separated on a $1.5 \mathrm{~m} \times 4 \mathrm{~mm}$ i.d. glass column packed with CAW (80-100 mesh) coated with 10\% FFAP (Pye-Unicam). The packing extended only to the base of the injector oven, to prevent pyrolysis of the liquid phase; and it was held in place by a tight wad of silica thread. After each analysis the column oven temperature was raised to $230^{\circ} \mathrm{C}$ for $c$. $10 \mathrm{~min}$, to remove high-boiling-point pyrolysis products, before cooling to $80^{\circ} \mathrm{C}$ for the next analysis.

Because the first six peaks were very high, the chromatograph amplifier attenuation was set to $512 \times 10$, and changed to $512 \times 1$ after $90 \mathrm{~s}$. The chart recorder was run at a speed of 10 $\mathrm{mm} / \mathrm{min}$ with a sensitivity of $10 \mathrm{mV}$.

After 100 analyses, the column was removed, the inner wall in the injection area was cleaned, and the top $5 \mathrm{~cm}$ of packing replaced. The first three analyses after this procedure were not used, and a test of pyrogram reproducibility was made using a control strain of $S$. aureus. This test was also made on a random basis.

\section{Numerical analysis of data and identification program}

A database consisting of four replicate pyrograms from each of 42 strains was collected and subjected to numerical analysis. The pyrogram data were reduced as follows: (1) inflections and peaks close to major peaks were removed because they were difficult to detect; (2) the six peaks with retention times $<100 \mathrm{~s}$ were removed because they were highly variable; (3) peak retention times were plotted as histograms, and peaks showing a bimodal distribution were removed. After these steps 22 peaks remained.

Peak heights were converted to percentages of the mean peak height of the 22 selected peaks for each pyrogram, to correct for the amount of specimen pyrolysed. These normalised peak heights (NPHs) were used in all subsequent calculations.

Taxonomic analysis. A mean within replicate variance was calculated for each peak from the NPH data for the 42 named isolates by the formula:

$$
V_{p}=\frac{1}{n} \times \sum_{i=1}^{i=n} \frac{r=R}{\sum_{r=1}^{r}\left(H_{p i r}-\bar{A}_{p i}\right)^{2}}
$$

where $V_{p}$ is the mean within isolate variance of peak $p$; $n$ is the number of isolates (42); $R$ is the number of replicate pyrograms for each isolate (4); $\mathrm{H}_{\mathrm{pir}}$ is the NPH for peak $\mathrm{p}$, isolate $\mathrm{i}$, replicate $r$; and $\bar{H}_{p i}$ is the mean NPH for peak $p$, isolate $i$. 
The corrected Euclidian distance between each pair of isolates in a 22 dimensional space defined by the peak height values was calculated from the equation:

$$
d_{x y}=\sqrt{\sum_{p=1}^{p=m} \frac{\left(\overline{\mathrm{H}}_{p x}-\overline{\mathrm{H}}_{\mathrm{py}}\right)^{2}}{\mathrm{~V}_{\mathrm{p}}}}
$$

where $d_{x y}$ is the Euclidian distance between isolates $x$ and $y ; m$ is the number of peaks $(22) ; \bar{H}_{p x}$ is the mean NPH for peak $p$, isolate $x ; \vec{H}_{p y}$ is the mean NPH for peak $p$, isolate $y$; and $V_{p}$ the mean within isolate variance of peak $p$; $d_{x y}$ is, therefore, a measure of dissimilarity between the pyrogram results for isolates $\mathrm{x}$ and $\mathrm{y}$.

The table of $d_{x y}$ values was examined, and the pair of isolates with the smallest value were regarded as a group at that $d_{x y}$ value. A set of mean NPHs was then calculated for this new group, new sets of $d_{x y}$ values were generated, and further groups formed until all 42 isolates formed a single group.

A similar analysis was used to compare the pyrograms of the control strain for quality control. A normal range of $d_{x y}$ values was derived from sequential replicate pyrograms, and any deviation from this was investigated and the cause corrected.

Identification. The multivariate statistical technique of discriminant analysis was used to produce a mathematical identification system for pyrograms of unnamed isolates. The analysis was performed using the subprogram 'Discriminant' from 'Statistical package for the social sciences' (Nie et al., 1975) and was run on a Prime 750 minicomputer. The NPH data for the 22 selected peaks from the four replicates of the 42 named isolates were the database. Using the discriminant functions produced by this program, an identification subroutine was added to the microcomputer peak detection program so that, on completion of an analysis, the computer immediately calculated the NPHs of the relevant peaks and then produced discriminant scores for the isolate. From these scores the computer printed the likelihood of the isolate being a member of each of the seven species. (Details of this analysis are available from the authors). The term likelihood means that a pyrogram with $0.5 \%$ likelihood of membership of a species would be expected to occur once in 200 analyses of isolates of that species.

Evaluation of PGLC identification system. The 100 strains examined in the trial were each subjected to a single PGLC analysis and identification by the computer program. PGLC identifications were accepted when the likelihood of membership was $\geqslant 0.5 \%$ for only one species. If the likelihood of membership was $\geqslant 0.5 \%$ for two or more species then the identification was regarded as equivocal, and if the likelihood of membership was $<0.5 \%$ for all species then the strain was regarded as unidentified.

\section{RESULTS}

\section{Control of pyrogram reproducibility}

During the analyses, there was a steady accumulation of tarry substances on the column wall in the pyrolysis area, on the silica thread plug, and in the top $5 \mathrm{~cm}$ of packing. This began to affect the pyrograms significantly after $c .100$ analyses, as noted by Stack et al. (1977). Therefore we instituted a similar regular cleaning and replacement procedure. Immediately after replacement of packing we obtained aberrant pyrograms, but they returned to normal after a few analyses. This phenomenon was more marked with a new column. The cleaning procedure was successful; replicate pyrograms of the control strain of S.aureus throughout the study were very similar, except on one occasion when the use of this control alerted us to an abnormally rapid accumulation of tars. A single column has been used for $>1200$ analyses without significant change in performance. The care in setting of carrier gas 
flow rates was also successful in controlling peak retention times; throughout the study retention times varied by between $\pm 1 \mathrm{~s}$ for the early peaks to $\pm 15 \mathrm{~s}$ for the last recorded peak at c. $910 \mathrm{~s}$ retention time. On the few occasions when mixed cultures were pyrolysed, or the wire was accidently handled during loading, aberrant pyrograms were obtained.

\section{Characterisation of the species by PGLC}

Characteristic pyrograms were obtained for each of the seven species included in the database. Visual inspection of the pyrograms was inadequate for identification to species level, a finding in agreement with the results of other studies (Quinn, 1976; Blomquist et al., 1979). However, the pyrograms could be divided into two clear groups by simple inspection. The 64 pyrograms from the strains of $S$. aureus and $S$. saprophyticus were clearly distinct from the pyrograms of the other five species; pyrograms typical of the two groups are shown in fig. 1 .

The results of the taxonomic analysis are summarised as a dendrogram (fig. 2). This represents an unweighted classification of the pyrograms; it was most encouraging to find that the seven clusters formed at $\mathrm{d}_{\mathrm{xy}}$ of $c$. 7 corresponded in general with the seven species groups obtained by biochemical identification. The seven clusters

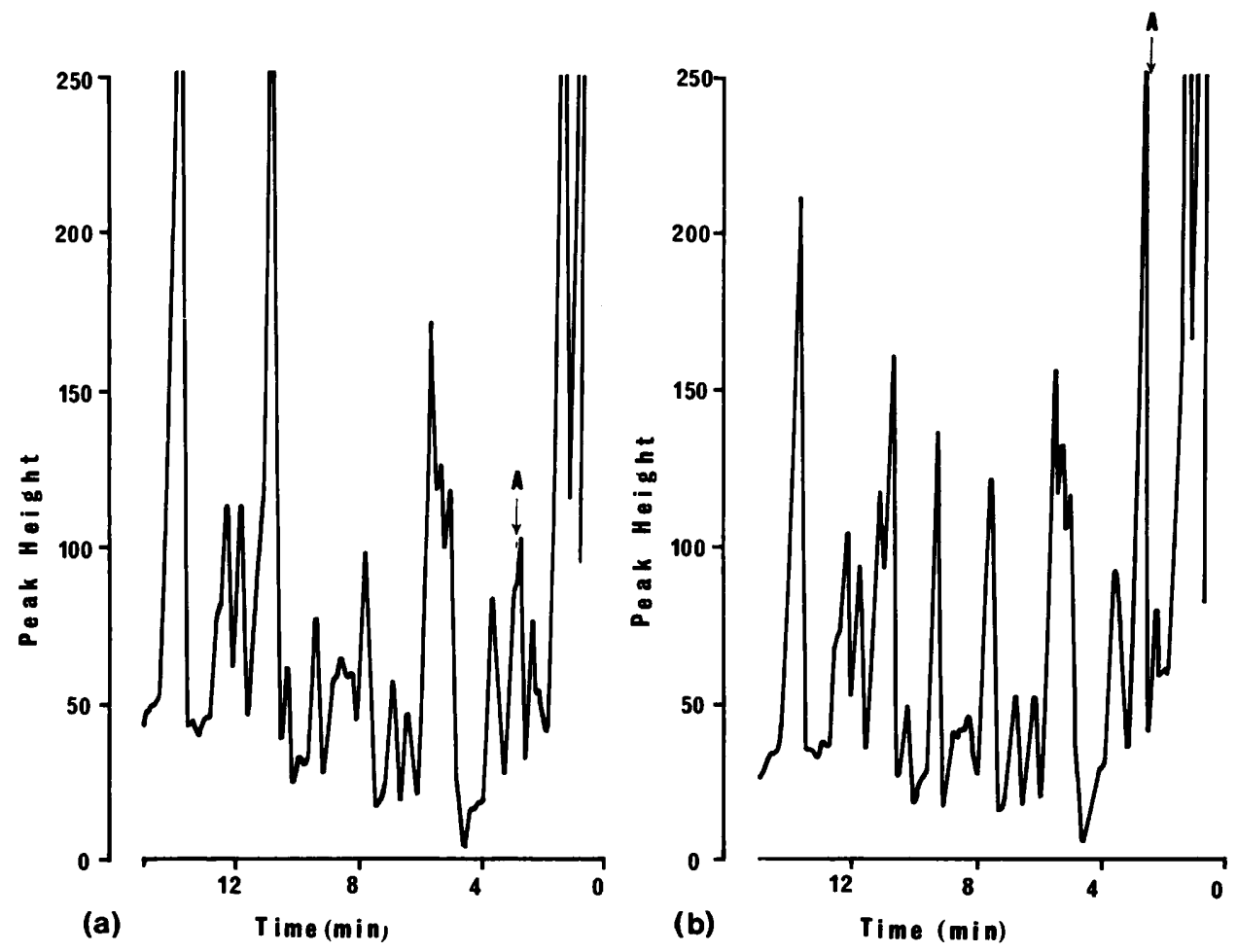

FIG. 1.-Typical pyrograms for (a) S. aureus and (b) S. epidermidis. Pyrolysis was started at time 0 min. The marker $A$ indicates the feature most useful in visual discrimination between the pyrograms. Pyrogram (a) is representative of all $S$. aureus and $S$. saprophyticus traces, whereas pyrogram (b) is representative of all $S$. epidermidis, $S$. hominis, $S$. haemolyticus, $S$. capitis and $S$. cohni strains at the level of visual discrimination. 


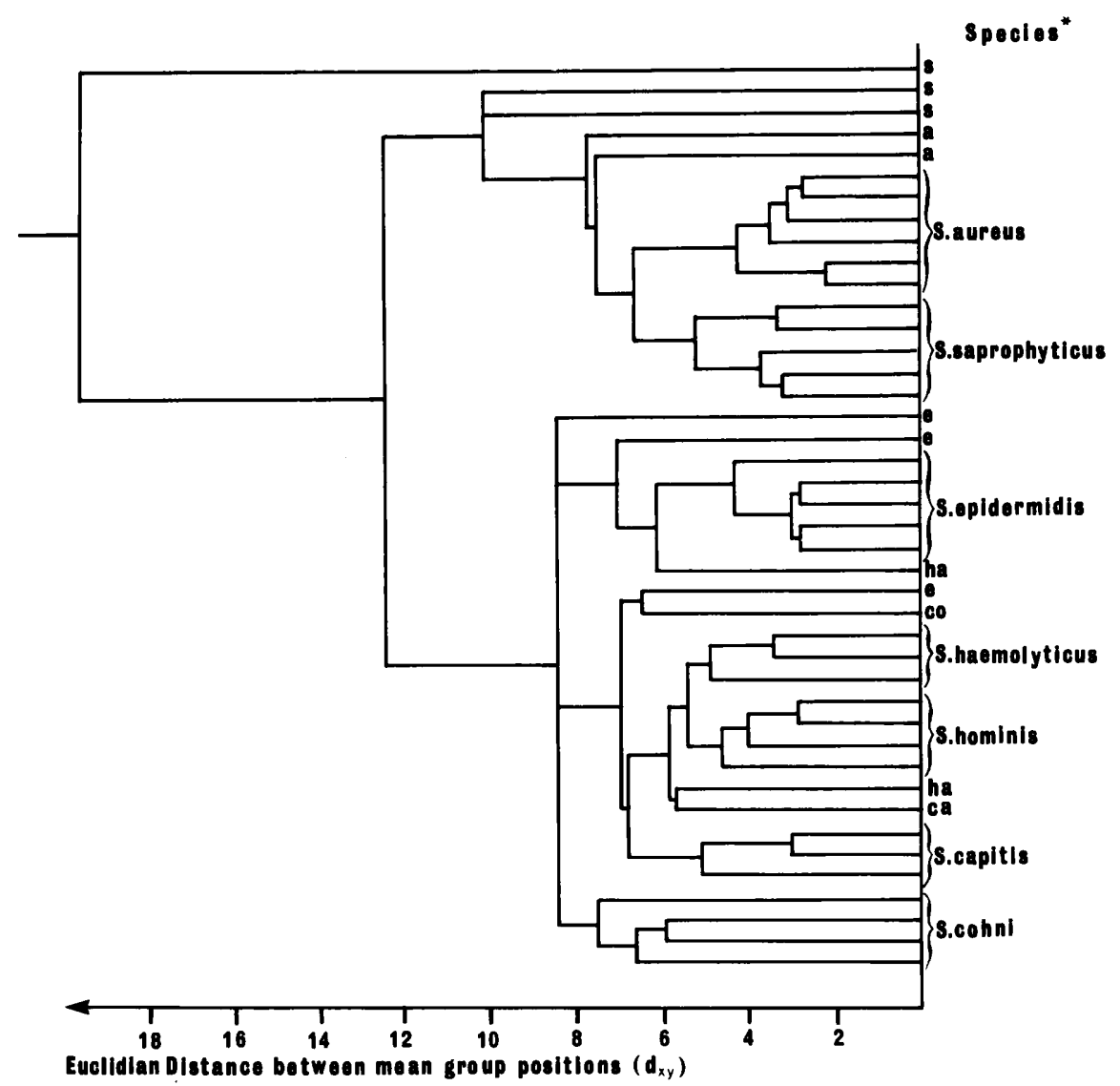

FIG. 2.-Dendrogram of 42 strains of Staphylococcus showing their relationship based upon PGLC data. * Identification based upon biochemical tests.

Key to species: $\mathrm{a}=S$. aureus, $\mathrm{s}=S$. saprophyticus, e $=S$. epidermidis, ha $=S$. haemolyticus, $\mathrm{ca}=S$. capitis, co=S. cohni.

formed two larger groups at $\mathrm{d}_{\mathrm{xy}}$ values of $c .12$ before forming a single cluster at $\mathrm{d}_{\mathrm{xy}}$ c. 18. As expected from the visual analysis, one of the two large groups contained the strains of S. aureus and S. saprophyticus, and the other group contained the strains of S. epidermidis, S. hominis, S. haemolyticus, S. capitis and S. cohni.

A pseudo-three-dimensional plot of the species mean scores on the first three discriminant functions (the species centroids) is shown in fig. 3. This plot represents $c$. $83 \%$ of the species discrimination attained; a six-dimensional plot would be required to represent the total discrimination. The distance between the species centroids in this type of plot is a measure of the ease of discrimination between typical species pyrograms.

\section{Evaluation of biochemical identification system}

Reproducibility of the biochemical tests was good; less than $5 \%$ disagreements occurred between replicate tests with the same strain in all but four tests. Disagree- 


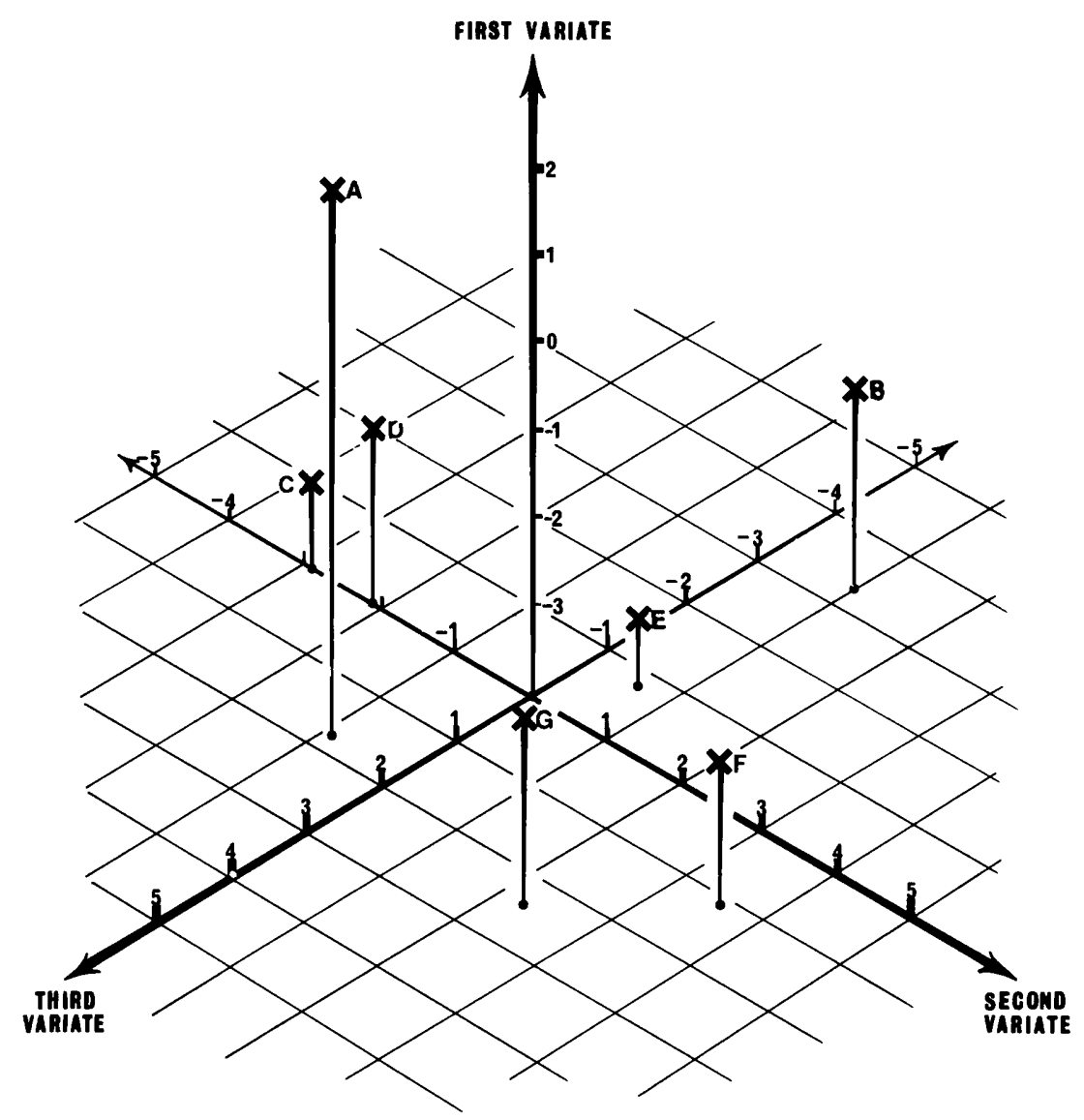

FIG. 3.-Pseudo-three-dimensional plot of mean species discriminant scores for the first three canonical variates.

Key to species: $\mathrm{A}=S$. aureus, $\mathrm{B}=S$. saprophyticus, $\mathrm{C}=S$. epidermidis, $\mathrm{D}=S$. hominis, $\mathrm{E}=S$. haemolyticus, $\mathrm{F}=S$. cohni, $\mathrm{G}=S$. capitis.

ments were found in $20 \%$ of replicate tests for colony pigmentation, probably because of the subjective nature of the distinction between white, buff and yellow colonies; there were $15 \%$ disagreements in replicate tests for the production of acid from melezitose which was expected because this sugar gave weak and delayed reactions that were difficult to discern; and there were disagreements in $10 \%$ of replicate tests for production of acid from galactose, and for production of phosphatase. Despite this variation, the final identifications resulting from the duplicate series of tests were identical for each of the 20 strains tested. Many delayed positive reactions were observed, with $15 \%$ of tests becoming positive only after incubation for 4 days; however, only one strain would have been given a different identity if all sugar reactions had been read after incubation for only 3 days.

Of the 142 strains examined, 61 gave results identical to the published descriptions of the species to which they were assigned, 51 differed in one reaction, and 24 in two reactions. Six differed in three or more reactions, and were regarded as unidentified in the biochemical scheme. Discrepancies were most common with strains identified as 
$S$. haemolyticus; 22 differences from the published description were noted in the 16 strains. Differences were found most commonly in the tests for production of acid from ribose (18 out of 142) and melezitose ( 9 out of 142). The identifications given by Dr Feltham for the 29 strains that he donated were identical to our biochemical identification.

\section{Evaluation of PGLC identification system}

The results of the PGLC identification system with 100 strains are summarised in tables I and III. Most strains (93) were identified by biochemical tests as species included in the database and the results for these strains are given in table I; of these strains, $83(90 \%)$ were identified correctly by PGLC. Four strains gave equivocal PGLC results, three were identified incorrectly and three remained unidentified. The results obtained with these strains are given in greater detail in table II.

TABLE I

Results of PGLC identification program with 93 isolates of seven species of Staphylococcus

\begin{tabular}{|c|c|c|c|c|c|}
\hline \multirow[b]{2}{*}{ Species* } & \multirow{2}{*}{$\begin{array}{l}\text { Number of } \\
\text { strains } \\
\text { tested }\end{array}$} & \multicolumn{4}{|c|}{$\begin{array}{l}\text { Number of strains that gave the } \\
\text { indicated result by PGLC }\end{array}$} \\
\hline & & Correct & Equivocal & Incorrect & No identification \\
\hline $\begin{array}{l}\text { S. aureus } \\
\text { S. saprophyticus } \\
\text { S. epidermidis } \\
\text { S. hominis } \\
\text { S. haemolyticus } \\
\text { S. capitis } \\
\text { S. cohni } \\
\text { Total }\end{array}$ & $\begin{array}{r}18 \\
9 \\
42 \\
5 \\
11 \\
5 \\
3 \\
93\end{array}$ & $\begin{array}{r}18 \\
9 \\
35 \\
3 \\
10 \\
5 \\
3 \\
3 \\
83\end{array}$ & $\begin{array}{l}0 \\
0 \\
2 \\
2 \\
0 \\
0 \\
0 \\
4\end{array}$ & $\begin{array}{l}0 \\
0 \\
3 \\
0 \\
0 \\
0 \\
0 \\
3\end{array}$ & $\begin{array}{l}0 \\
0 \\
2 \\
0 \\
1 \\
0 \\
0 \\
3\end{array}$ \\
\hline
\end{tabular}

* Species identified by biochemical tests (see Methods).

TABLE II

Results obtained with the 10 strains that gave an equivocal or incorrect identification by PGLC and were identified by biochemical tests as a species included in the database

\begin{tabular}{|c|c|c|c|c|c|}
\hline \multirow[b]{2}{*}{ Species* } & \multirow{2}{*}{$\begin{array}{l}\text { Number of } \\
\text { discrepancies } \dagger\end{array}$} & \multicolumn{4}{|c|}{ Result of PGLC analysis } \\
\hline & & First choice & $\mathrm{L} \% \ddagger$ & Second choice & $\mathrm{L} \% \ddagger$ \\
\hline $\begin{array}{l}\text { S. hominis } \\
\text { S. hominis } \\
\text { S. epidermidis }\end{array}$ & $\begin{array}{l}0 \\
0 \\
0\end{array}$ & $\begin{array}{l}\text { S. hominis } \\
\text { S. hominis } \\
\text { S. epidermidis }\end{array}$ & $\begin{array}{l}11 \\
44 \\
24\end{array}$ & $\begin{array}{l}\text { S. epidermidis } \\
\text { S. haemolyticus } \\
\text { S. haemolyticus }\end{array}$ & $\begin{array}{l}7 \\
3 \\
2\end{array}$ \\
\hline $\begin{array}{l}\text { S. epidermidis } \\
\text { S. epidermidis } \\
\text { S. epidermidis } \\
\text { S. epidermidis }\end{array}$ & $\begin{array}{l}2 \\
1 \\
1 \\
2\end{array}$ & $\begin{array}{l}\text { S. haemolyticus } \\
\text { S. haemolyticus } \\
\text { S. hominis } \\
\text { S. haemolyticus }\end{array}$ & $\begin{array}{l}2 \\
2 \\
1 \\
2\end{array}$ & $\begin{array}{l}\text { S. epidermidis } \\
\text { S. hominis } \\
\text { S. haemolyticus } \\
\text { S. capitis }\end{array}$ & $\begin{array}{l}1 \\
0.7 \\
0.06 \\
0.05\end{array}$ \\
\hline $\begin{array}{l}\text { S. epidermidis } \\
\text { S. haemolyticus } \\
\text { S. epidermidis }\end{array}$ & $\begin{array}{l}0 \\
1 \\
2\end{array}$ & $\begin{array}{l}\text { S. hominis } \\
\text { S. haemolyticus } \\
\text { S. hominis }\end{array}$ & $\begin{array}{l}0 \cdot 3 \\
0 \cdot 1 \\
0 \cdot 06\end{array}$ & $\begin{array}{l}\text { S. capitis } \\
\text { S. hominis } \\
\text { S. haemolyticus }\end{array}$ & $\begin{array}{l}0.009 \\
0.0004 \\
0.0002\end{array}$ \\
\hline
\end{tabular}

* Species identified by biochemical methods (see Methods).

$\dagger$ Number of biochemical tests in which the strain gave a result different from that expected in the accepted description of the species.

$\ddagger$ Likelihood $(\%)$ of species membership for the indicated PGLC identification. 
TABLE III

Results of PGLC identification with seven isolates that were not identified by biochemical tests as belonging to the seven species in the database

\begin{tabular}{|c|c|c|c|}
\hline \multirow[b]{2}{*}{ Species } & \multirow{2}{*}{$\begin{array}{l}\text { Number of } \\
\text { strains } \\
\text { tested }\end{array}$} & \multicolumn{2}{|c|}{$\begin{array}{l}\text { Number of strains that gave } \\
\text { the indicated results by PGLC }\end{array}$} \\
\hline & & Incorrect & Not identified* \\
\hline $\begin{array}{l}\text { S. simulans } \\
\text { Not identified } \\
\text { Total }\end{array}$ & $\begin{array}{l}1 \\
6 \\
7\end{array}$ & $\begin{array}{l}0 \\
3 \\
3\end{array}$ & $\begin{array}{l}1 \\
3 \\
4\end{array}$ \\
\hline
\end{tabular}

* A non-identification for these strains is a correct result.

Only one of the 100 strains was identified by biochemical tests as a species other than those included in the database-S. simulans - and six remained unidentified. The results for these strains are given in table III. Isolates of species other than those included in the database could not be expected to be identified correctly by PGLC.

The mean likelihood of PGLC identification of the 83 strains for which PGLC and biochemical identification agreed was $28 \%$ and the number of differences from the accepted species descriptions in biochemical tests was 67 . The PGLC results with three strains gave good likelihoods for the 'correct' identification but must be regarded as equivocal because they also gave acceptable likelihoods for 'incorrect' species. There were no discrepant results in the biochemical patterns of these strains. By contrast, the mean likelihood of PGLC identification of the seven isolates shown in table II, for which the PGLC identification did not give the 'correct' species as first choice, was $0.8 \%$; and there were nine differences from the species description in biochemical tests.

\section{DisCUSSION}

Conventional identification techniques depend mainly on biochemical tests, many of which require several days for completion. The introduction of micromethods has shortened this time to $<24 \mathrm{~h}$ in some instances, but PGLC offers a means of identification in $<30 \mathrm{~min}$ after obtaining a pure culture. The purpose of this project was to adapt PGLC for use in a routine hospital laboratory. We have overcome some of the technical problems, and we have improved data acquisition, instituted an internal quality control system, and produced an identification program. Additionally, several improvements suggested by MacFie, Gutteridge and Norris (1978) have been investigated, including empirical verification of the accuracy of identification, selection of variables measured, and prolongation of column life.

For routine use, specimen preparation must be simple and rapid. Other workers have used freeze-dried washed cells (Wickman, 1977) or cells grown on filter membranes (Oxborrow et al., 1976) to improve reproducibility, but such methods are unacceptable for a routine system. We obtained good discrimination to species level with a few colonies taken directly from a solid medium; and identification from a primary isolation plate would be possible if well separated characteristic colonies were present. Meuzelaar, Kistemaker and Tom (1975) also used colonies taken directly from a solid medium. However, the practical requirements of classical microbiology for pure inocula apply equally to PGLC and to biochemical tests. 
A normalisation procedure is necessary because of variation in the weight of material pyrolysed (Blomquist et al., 1979). Total peak height over a selected set of peaks is commonly used as a correction factor (MacFie et al., 1978). This approach is based on the assumption that all peaks are affected proportionally by variation in specimen weight. We have found no proof of this assumption in published work but its empirical use was justified by the results of our studies. However, discrimination due to large differences in a single peak may be artificially distributed over all the peaks by this normalisation; e.g., the very tall peak at a retention time of $157 \mathrm{~s}$ in the S. epidermidis pyrogram (feature A, fig.1) contributes so much to the normalisation factor that not only is the NPH for this peak larger but the other peaks appear smaller when compared with $S$. aureus. This may cause the discriminant analysis to include a larger number of peaks than is strictly necessary unless non-discriminating peaks are eliminated from the normalisation and the revised data resubmitted to 'Discriminant' in a cyclic process. O'Donnell, MacFie and Norris (1980) showed that species could be discriminated on a small number of peaks - hence the drastic pruning of the data. Reliability of peak height detection, measurement and resolution was assessed over the range of species when our characterisation database was complete, and 18 of the 40 peaks were eliminated.

The baseline shift correction of the data acquisition program was essential, because a negative baseline shift due to imbalance between the columns during the temperature program, which would affect the recorded peak heights, cannot be detected on either the chart record or the computer; therefore a small positive shift was introduced and then subtracted from subsequent pyrograms. Without this, random day to day variation would have affected different peaks to different extents according to their retention time. Failure to produce baseline-resolved peaks in pyrograms may be due to a background of unresolved peaks, but we believe that this effect is due mainly to the fusion of the bases of the resolved peaks; hence we have corrected only for baseline shift. Other workers have used artificial baseline corrections produced by joining troughs (O'Donnell et al., 1980). The use of isothermal PGLC (French et al., 1981) eliminates the need for a baseline shift correction.

Many workers have commented on short column life and poor inter-column reproducibility (Seviour et al., 1974; Wickman, 1977; Brosseau and Carmichael, 1978; French et al., 1980). We found that cleaning and replacement of packing after each 100 analyses allowed a single column to be used for $>1200$ analyses without detectable deterioration, confirming the findings of Stack et al. (1977). The pattern of separation on a new or cleaned column changed during conditioning, which suggests that the liquid phase may be modified by pyrolysis products.

The life of the column may have been increased by using FFAP as the liquid phase. It has a higher thermal stability than Carbowax 20M, allowing higher column temperatures to be used to remove high-boiling-point compounds between analyses without excessive 'bleed' of the liquid phase.

Computerisation of data acquisition and analysis is essential for the routine application of PGLC tu bacterial identification. PGLC produces large amounts of numerical data-10560 numbers in our database. The computer programs were essential for recording and manipulating these data. Many workers use automatic integrators for acquisition of gas-liquid chromatography data. We chose a computerADC system measuring peak heights, rather than an integrator measuring peak areas, 
because of its versatility and cost advantage; the addition of the identification subroutine provided an automated identification system that exploited the speed of PGLC.

Quality control of laboratory techniques is essential, especially with the introduction of advanced technology. Daily control of retention time reproducibility was most important for accurate peak recognition. The control of pyrogram reproducibility with a single isolate assured us of the continuing reliability of the column, and, on one occasion, alerted us to problems.

The taxonomic analysis that we used corresponds in principle to the pair-group method of cluster analysis (Sokal and Sneath, 1963), using unweighted cluster means, and produced acceptable results. Percentage similarity coefficients are used more commonly than Euclidian distance in bacterial taxonomy because they are appropriate to the analysis of + or - characters, whereas Euclidian distance is appropriate to continuous variables such as peak heights.

Canonical variate or discriminant analysis has been used in recent work on PGLC (MacFie et al., 1978; O'Donnell et al., 1980). This produces formulae that discriminate between pyrograms of various species of bacteria, and is easy to use but cannot be performed on a microcomputer; however it is used only for characterisation, not for the peak detection or identification routines.

The centroid data produced by discriminant analysis may be useful in the indication of possible problem areas. The plot of centroids in fig. 3 shows that $S$. epidermidis, $S$. hominis and $S$. haemolyticus are the closest neighbours, which is confirmed by exact calculation of Euclidian distance in six-dimensions. This implies that discrimination between these three species may be difficult whereas $S$. aureus is widely separated from the other species and should present few problems. This was confirmed by the results of the evaluation study: $S$. aureus strains were identified with $100 \%$ accuracy and with very low probabilities of membership of the other species, whereas all the equivocal results from PGLC occurred in the $S$. epidermidis/S. hominis/ S. haemolyticus area.

The agreement between the biochemical and PGLC identification schemes was as good as could be expected from a comparison of two distinct biochemical schemes. The unusually high number of discrepant biochemical reactions of the 16 strains identified as $S$. haemolyticus suggests that this group may be heterogeneous and would merit further study. The high rate of discrepancies in the tests for acid production from ribose and melezitose among the strains is puzzling; any problem with the methodology should also have affected the other carbohydrate reactions, which were performed in the same basal medium. We note that similar discrepancies occurred in the study of Wilkinson, Maxwell and Schauz (1980) who also found most aberrant reactions occurred with these sugars. The species descriptions (Kloos and Schleifer, 1975a; Schleifer and Kloos, 1975) and the identification matrix of Fel tham and Sneath (1982) also show discrepancies in the expected results for these two sugar reactions.

There was an unusually high number of biochemical discrepancies with the species descriptions for the group of seven organisms in table II which were identified biochemically, but for which PGLC gave an incorrect result as first choice. This suggests to us that some biochemically atypical strains may give abberant PGLC patterns. An alternative explanation is that some atypical strains were mis-identified in the biochemical scheme. 
This study has shown that, despite the difficulty of the technique, PGLC can be used successfully in the identification of strains of a group of related species. Other workers have found problems in inter-column and inter-apparatus reproducibility (Stack et al., 1977; French et al., 1980) and any advance here would aid the introduction of PGLC as a routine identification technique. PGLC requires sequential rather than batch analysis, which could also lead to problems in routine use. However these problems are unlikely to remain unsolved. The mathematics can be handled by simple programs, and the computer link provides an identification system that has given rapid and reliable results.

We thank Dr C.I.Franks and Mr S.A.Pearson of the Department of Medical Physics, Royal Hallamshire Hospital, for their design and construction of the buffer-amplifier, Dr R.K.A.Feltham for the staphylococci, Mrs V.Ede for her help in identifying the isolates, Professor B.I.Duerden and Dr D.M.Harris for their advice and encouragement, and especially the late $\mathrm{Dr}$ J.Colquhoun for his enthusiasm and help in starting this study.

\section{REFERENCES}

Blomquist, G., Johansson, E., Soderström, B. AND Wold, S. 1979. Data analysis of pyrolysis-chromatograms by means of SIMCA pattern recognition. Journal of Analytical and Applied Pyrolysis, 1, 53-65.

Brosseau, J. D. AND CARmichael, J. W. 1978. Pyrolysis gas liquid chromatography applied to a study of variation in Arthroderma tuberculatum. Mycopathologia, 63, 69-79.

BUhleR, C. AND SimON, W. 1970. Curie-point pyrolysis gas chromatography. Journal of Chromatographic Science, 8, 323-329.

Cowan, S. T. 1974. Cowan and Steel's Manual for the identification of medical bacteria 2nd ed., Cambridge University Press, Cambridge.

DrUCKeR, D. B. 1976. Gas-liquid chlomatographic chemotaxonomy In Methods in microbiology, vol.9, edited by J.R.Norris, Academic Press, London, pp. 51-125.

Feltham, R. K. A. 1979. A taxonomic study of the Micrococcaceae. Journal of Applied Bacteriology, 47, 243-254.

Feltham, R. K. A. AND SNeath, P. H. A. 1982. Construction of matrices for computer-assisted identification of aerobic Gram-positive cocci. Journal of General Microbiology, 128, 713-720.

French, G. L., PhilliPS, I. AND ChINN, S. 1981. Reproducible pyrolysis-gas chromatography of micro-organisms with solid stationary phases and isothermal oven temperatures. Journal of General Microbiology, 125, 347-355.

French, G. L., Gutteridge, C. S. AND PhilliPS, I. 1980. Pyrolysis gas chromatography of Pseudomonas and Acinetobacter species. Journal of Applied Bacteriology, 49, 505-516.

GutTERIDGE, C. S. AND NoRRIS, J. R. 1979. The application of pyrolysis techniques to the identification of micro-organisms. Journal of Applied Bacteriology, 47, 5-43.

KLOOS, W. E. AND SCHLEIFER, K. H. 1975a. Isolation and characterisation of staphylococci from human skin. II. Descriptions of four new species, Staphylococcus warneri, Staphylococcus capitis, Staphylococcus hominis and Staphylococcus simulans. International Journal of Systematic Bacteriology, 25, 62-79.

Kloos, W. E. AND Schleifer, K. H. 1975b. Simplified scheme for routine identification of human Staphylococcus species. Journal of Clinical Microbiology, 1, 82-88.

MACFIE, J. H., GUTTERIDGE, C. S. AND NoRRIS, J. R. 1978. Use of canonical variates analysis in differentiation of bacteria by pyrolysis gas-liquid chromatography. Journal of General Microbiology, 104, 67-74.

Meuzelaar, H. L. C., Kistemaker, P. G. and Tom, A. 1975. Rapid and automated identification of micro-organisms by Curie-point pyrolysis techniques, I. Differentiation of bacterial strains by fully automated Curie-point pyrolysis gas-liquid chromatography. In New approaches to the identification of micro-organisms, edited by C.-G.Heden and T.Illeni, John Wiley and Sons, New York, pp. 165-178. 
Nie, N. H., Hull, C. H., Jenkin, J. G., Steinbrenner, K. And Bent, D. H. 1975. Statistical Package for the Social Sciences, McGraw-Hill, New York.

O'Donnell, A. G., MACFIE, H. J. H. AND NoRRIS, J. R. 1980 . An investigation of the relationship between Bacillus cereus, Bacillus thuringiensis and Bacillus mycoides using pyrolysis gas-liquid chromatography. Journal of General Microbiology, 119, 189-194.

Oxborrow, G. S., Fields, N. D. ANd Puleo, J. R. 1976. Preparation of pure microbiological samples for pyrolysis gas-liquid chromatography studies. Applied and Environmental Microbiology, 32, 306-309.

QuiNN, P. A. 1976. Identification of micro-organisms by pyrolysis: the state of the art. In Proceedings of the 2nd international symposium on Rapid methods and automation in microbiology, Learned Information Ltd, Oxford, pp. 178-186.

REINER, E. AND EWING, W. H. 1968. Chemotaxonomic studies of some Gram negative bacteria by means of pyrolysis-gas-liquid chromatography. Nature, 217, 191-194.

SCHLEIFER, K. H. AND KLOOS, W. E. 1975. Isolation and characterisation of staphylococci from human skin. I. Amended descriptions of Staphylococcus epidermidis and Staphylococcus saprophyticus and descriptions of three new species: Staphylococcus cohnii, Staphylococcus haemolyticus, and Staphylococcus xylosus. International Journal of Systematic Bacterio$\log y, 25,50-61$.

SeKhon, A. S. AND CARMichael, J. W. 1973. Column variation affecting a pyrolysis gas-liquid chromatographic study of strain variation in two species of Nannizzia. Canadian Journal of Microbiology, 19, 409-411.

Seviour, R. J., Chilvers, G. A. AND Crow, W. D. 1974. Characterisation of eucalypt mycorrhizas by pyrolysis gas chromatography. New Phytology, 73, 321-332.

Sokal, R. R. And SNeath, P. H. A. 1963. Principles of Numerical Taxonomy, W.H.Freeman and Co., London.

Stack, M. V., Donoghue, H. D., Tyler, J. E. and Marshall, M. 1977. Comparison of oral streptococci by pyrolysis gas-liquid chromatography. In Analytical Pyrolysis edited by C.E.R. Jones and C.A.Cramers, Elsevier, Amsterdam, pp. 57-68.

Wilkinson, B. J., MaXWell, S. AND SchaUZ, S. M. 1980. Classification and characteristics of coagulase-negative, methicillin resistant staphylococci. Journal of Clinical Microbiology, 12, 161-166.

Wickman, K. 1977. Pyrolysis-gas-liquid chromatography of mycobacteria. Acta Pathologica et Microbiologica Scandinavica, Section B, Suppl. 259, 49-53. 